\title{
Howard E. Katz appointed JMR Associate Editor, Polymers and Organic Materials
}

I am pleased to announce the appointment of Professor Howard E. Katz as Associate Editor, Polymers and Organic Materials. Professor Katz is the first associate editor in this position, which was created to help broaden JMR's coverage of materials topics, part of the journal's strategic guidance from the MRS Board of Directors. With an associate editor exclusively responsible for directing the peer reviews and decisions for manuscripts on polymers and organic materials, I want to demonstrate $J M R$ 's commitment to a high quality home for these topics. We are interested in receiving manuscripts that provide new insights and an advance in the scientific understanding of these materials.

Professor Katz began his career at Bell Laboratories where he became a Distinguished Member of the Technical Staff. His research areas have included organic/hybrid materials, especially organic semiconductors and photonic polymers, novel conjugated compounds, new approaches to fabrication, and high field devices. He has numerous journal publications, 36 US patents, and over 100 invited lectures. Professor Katz recently moved to Johns Hopkins University where he is a Professor in the Department of Materials Science and Engineering, with a joint appointment in the Department of Chemistry. He is a longtime active member of MRS and served as MRS President in 2004.

I look forward to working with Professor Katz and receiving manuscripts on materials research of polymers and organic materials.

Very truly yours,

Gordon Pike

Editor-in-Chief 